\title{
The Effect Of Perioperative I.V. Corticosteroids On Hearing Outcome Following Stapedotomy
}

\author{
Çağrı Çelik ${ }^{1}$, Mehmet Emrah Ceylan² Aynur Aliyeva ${ }^{3}$ Ufuk Düzenli ${ }^{4}$ Abdullah Dalgıç ${ }^{3}$ \\ ${ }^{1}$ Sirnak State Hospital, ENT Clinic, Sirnak - Turkey \\ ${ }^{2}$ Private Davraz Hospital, ENT Clinic, Isparta - Turkey \\ ${ }^{3}$ Health Sciences University, Bozyaka Training and Research Hospital, ENT Department, Izmir - Turkey \\ ${ }^{4}$ Van Yüzüncü Yil University, Medical Faculty, ENT Department, Van - Turkey
}

\begin{abstract}
Objective: The purpose of this study is to investigate the effect of steroids on postoperative hearing outcome in patients with a clinical diagnosis of otosclerosis, who received intraoperative steroid treatment during surgery for conductive-type hearing loss.

Methods: Between January 2014 and January 2017, 106 patients, comprising 43 men $(40.6 \%)$ and 63 women (59.4\%) between the ages of $18-64$ (mean age: $44.1 \pm 11.5$ years), who had been diagnosed with otosclerosis resulting in conductive-type hearing loss, were included in the study. The audiometric values obtained for patients who had received intraoperative intravenous steroids were analysed on a retrospective basis by comparing the pre- and post-operative situation. The group of all patients was then subdivided into two groups on the basis of whether or not they had received intraoperative steroids. These groups were then evaluated in terms of pre- and post-op-
\end{abstract}

erative bone and air conduction levels and the differences investigated statistically.

Results: Postoperative bone conduction averages for all the patients in both Group 1 and Group 2 were significantly improved at all frequencies, except at $4000 \mathrm{~Hz}$, compared to the preoperative mean value. However, there was no statistically significant difference observed between patients who did receive intra-operative single-dose IV corticosteroid injections and patients who did not receive IV corticosteroid injections group in terms of preoperative and postoperative air-bone conduction levels.

Conclusion: It is not necessary routinely to administer systemic corticosteroids in order to prevent perioperative sensorineural hearing loss during surgery for otosclerosis. However, perioperative corticosteroids may be helpful in preventing sensorineural hearing loss when there are conditions present that can lead to inner ear damage during the operation.

\section{Introduction}

Otosclerosis is a disorder which can lead to conductive and/or sensorineural hearing loss through fixation of the stapes' footplate and resorption of the cochlear bone. The clinical presentation is of gradually progressive hearing loss and tinnitus. Whilst surgical perforation of the oval window and implantation of a prosthetic device may correct the progressive type of hearing loss, the operation may also cause sensorineural hearing loss.

Steroid preparations are frequently utilised in ENT practice with the intention of preventing or treating abrupt hearing loss, acoustic trauma, autoimmune disorders affecting the inner ear, facial paralysis and, especially, damage to the inner ear. It has been demonstrated experimentally [1] that topical application of steroids in cochlear implant surgery confers functional benefit.

The aim of this study is to investigate the postoperative effects on hearing of providing intravenous steroids intraoperatively to patients with a clinical diagnosis of otosclerosis who are being operated on for conductive hearing loss.
Correspondence: Mehmet Emrah Ceylan, Özel Davraz Yaşam Hastanesi KBB Kliniği, ISPARTA e-mail:mrhcyln@gmail.com

Received: April 2, 2018; Accepted: July 24, 2018
Online available at:

www.entupdates.org

DOI:10.32448/entupdates.45898
回唡口 施福 


\section{Materials And Methods}

In this trial, patients attending the ENT clinic at the Bozyaka Teaching and Research Hospital in Izmir, Turkey, with a clinical diagnosis of otosclerosis between January 2014 and January 2017 were retrospectively evaluated. Since the trial was undertaken retrospectively, no ethical approval was sought from the Ethics Committee. Cases where the patient had a clinical diagnosis of otosclerosis and had been operated on for conductive hearing loss were included in the study. Exclusion criteria were: revision surgery, conductive hearing loss due to any other disorder (tympanosclerosis, discontinuity of the ossicles and adhesions etc), age below 18 years or above 70 years. The operation notes, audiological record and information about intravenous injections given during the operation in 106 cases were reviewed retrospectively.

Cases were assigned to either Group 1 ( $\mathrm{n}=56$ : intraoperative use of i.v. steroids for any reason - difficult intubation, exposure of the facial nerve etc), or Group 2 ( $n=50$ : no intraoperative steroid use). The patients' age, sex and follow-up period were recorded and the operative notes reviewed. The patients' audiological measures both pre- and post-operatively were evaluated alongside the i.v. steroid status. The latest existing audiological assessment was taken as the baseline.

Audiological evaluation was undertaken in accordance with the guidelines of the American Academy of Otorhinolaryngology and Head and Neck Surgery ${ }^{[2]}$. All the audiological values for the bony and air pathways obtained both prior to and following surgery were noted in both groups. For both groups the amount and rate of change between the preoperative and postoperative periods in the average values obtained at frequencies of 500, 100, 2000 and 4000 Hertz were evaluated for the bone and air pathways on the basis of both frequency and average value to see if significant differences existed.

The statistical analysis was performed with the paired T-test using the SPSS (Statistical Package for Social Sciences) 16.0 software application.

\section{Results}

The participants in the study were all between 18 and 64 years old. The average age was $44.1 \pm 11.5$ years. 63 cases were female $(59.4 \%)$ and 43 male $(40.6 \%)$. The two comparison groups were similar in terms of age and sex distri- bution. Of the 106 cases included in the study, 44 had local and 82 general, anaesthesia for the operation. Of the 106 cases operated upon, all underwent stapedotomy.

55 patients $(51.8 \%)$ had a right-sided, and $51(48.2 \%)$ a left-sided operation. During the operation it was observed that they received a single dose of methylprednisolone intravascularly at a dosage of $1 \mathrm{mg} / \mathrm{kg}$ weight. The follow-up period following surgery was between 3 and 40 months (16.4 months on average).

Moving onto the results of the audiological assessment: before grouping of any kind occurred the average gain values for bone conduction were separately ascertained for frequencies of 500, 1000, 2000 and 4000Hz.

- For all the patients a statistically significant improvement was observed in the average values for bone conduction postoperatively at 500, 1000 and $2000 \mathrm{~Hz} \quad(\mathrm{p}<0.05)$ (Table 1).

- At $4000 \mathrm{~Hz}$, no such statistically significant improvement was apparent $(p>0.05)$. Looking at the level of improvement, this was greatest for bony conduction at $2000 \mathrm{~Hz}(\mathrm{p}<0.001)$. (Table 1$)$

When the value for all the cases obtained at frequencies of $500,1000,2000$ and $4000 \mathrm{~Hz}$ for the average value of bony conduction were taken together, a statistically significant improvement was seen $(\mathrm{p}<0.05)$ (Table 1).

Group 1 and Group 2 were examined from the point of view of gains in bone conduction at each of the separate frequencies. The amount of gain in both groups is shown in Table 2. According to these results, no statistically significant difference was found between the two groups in terms of bone pathway gain at $500,1000,2000$ or $4000 \mathrm{~Hz}$ ( $>0.05$ ) (Table 2). When the average values for pre- and post-operative bony conduction and the gain in bony conduction following operation were compared in Group 1 and Group 2, no statistically significant differences were observed ( $\mathrm{p}>0.05$ ) (Table 3).

Comparing vocal discrimination scores in Groups 1 and 2 for all the cases:

- In Group 1, the vocal discrimination score postoperatively was observed to have improved at a significant level compared to the preoperative condition $(\mathrm{p}<0.05)$ (Table 4).

- In Group 2, the vocal discrimination score postoperatively was observed not to have undergone significant change compared to the preoperative condition ( $p>0.05)$ (Table 4). 
Table 1: Comparison of preoperative and postoperative bone conduction levels

\begin{tabular}{llllll}
\hline $\begin{array}{l}\text { All Patients } \\
(106 \text { patients) }\end{array}$ & $\begin{array}{l}\text { Preop } \\
\text { Mean } \pm \text { SD }(\mathrm{dB})\end{array}$ & $\begin{array}{l}\text { Postop } \\
\text { Mean } \pm \text { SD }(\mathrm{dB})\end{array}$ & $\begin{array}{l}\text { Preop.-Postop. } \\
\text { Mean difference }\end{array}$ & P Value & Results \\
\hline $\begin{array}{l}500 \mathrm{~Hz} \\
\text { bone conduction }\end{array}$ & $20,79 \pm 12,3$ & $16,54 \pm 11,3$ & $4,25 \pm 11,34$ & 0,00018 & $\mathrm{P}<0,{ }^{*}$ \\
$\begin{array}{l}1000 \mathrm{~Hz} \\
\text { Bone conduction }\end{array}$ & $26,16 \pm 14$ & $20,18+13$ & $5,98 \pm 12,48$ & 0,0000027 & $P<0,001^{* * *}$ \\
$\begin{array}{l}2000 \mathrm{~Hz} \\
\text { Bone conduction }\end{array}$ & $32,52 \pm 15,6$ & $26,49 \pm 15,2$ & $6,02 \pm 11,75$ & 0,00000061 & $\mathrm{P}<0,001^{* * *}$ \\
$\begin{array}{l}4000 \mathrm{~Hz} \\
\text { Bone conduction }\end{array}$ & $28,13 \pm 19,5$ & $28,08 \pm 16,4$ & $0,046 \pm 14,13$ & 0,97 & $P>0,05, \mathrm{~ns}$ \\
$\begin{array}{l}\text { Bone conduction (Mean) } \\
(500,1000,2000,4000)\end{array}$ & $26,9 \pm 13,62$ & $22,82 \pm 13,5$ & $4,07 \pm 11,4$ & 0,00024 & $P<0,05^{*}$ \\
\hline
\end{tabular}

Postoperative air-bone gap values:

-All patients:

- Below $10 \mathrm{~dB}: \quad 34$ patients $\quad(32 \%)$

- Between 11-20 dB: 47 patients (44,3\%)

- Between 21-30 dB: 22 patients (20,7\%)

- Over $30 \mathrm{~dB}$ : 4 patients $\quad(3,77 \%)$

Group 1:

- Below $10 \mathrm{~dB}$ : 12 patients $(21,4 \%)$

- Between 11-20 dB: 26 patients (46,4\%)

- Between 21-30 dB: 16 patients (28,5\%)

- Over $30 \mathrm{~dB}$ : 2 patients $\quad(3,57 \%)$

Group 2:

- Below $10 \mathrm{~dB}$ : 22 patients (44\%)

- Between 11-20 dB: 21 patients (42\%)

- Between 21-30 dB: 6 patients (12\%)

- Over $30 \mathrm{~dB}$ : 2 patients (4\%)

\section{Discussion}

The aim of surgery in otosclerosis is to restore hearing that has been progressively damaged by impaired movement of the ossicles resulting from sclerosis. In our clinical setting, reverse stapedotomy (intact bridge stapedotomy), as outlined by Fisch, is the routine operation performed ${ }^{[3]}$.

There are multiple studies ongoing concerning the use and efficacy of steroids to avoid cochlear injury in cochlear implant surgery and many other otological procedures ${ }^{\text {[4- }}$ 6]. In our study we also investigated whether intravenous steroids have any effect on hearing outcomes by comparing cases where i.v. steroids had been given intraoperatively with those where it had not, by retrospectively reviewing the audiological results.

Audiologically speaking, the presence of conductive-type hearing loss plus the appearance of Carhart's notch at around $2000 \mathrm{~Hz}$ frequency are findings suggestive of otosclerosis. The amelioration that appears in the bony pathway postoperatively (the Carhart effect) has been estimated as between $5-10 \mathrm{~dB}$ at $500 \mathrm{~Hz}, 10-20 \mathrm{~dB}$ at $1000 \mathrm{~Hz}$, $15-30 \mathrm{~dB}$ at $2000 \mathrm{~Hz}$ and $5-20 \mathrm{~dB}$ at $4000 \mathrm{~Hz}^{[7]}$. The increase in bony conduction is not solely at $2000 \mathrm{~Hz}$, but also occurs

Table 2: Evaluation of bone conduction gain of Groups.

\begin{tabular}{lllll}
\hline Bone conduction gain & \multicolumn{2}{c}{ Mean Value \pm SD (dB) } & P Value & Results \\
& $\begin{array}{c}\text { Group 1 } \\
\text { (Steroid +) }\end{array}$ & $\begin{array}{c}\text { Group 2 } \\
\text { (Steroid - ) }\end{array}$ & & P>0,05, ns \\
\hline $500 \mathrm{~dB}$ postop.-preop. & $5,00 \pm 13,00$ & $3,43 \pm 9,25$ & 0,47 & $\mathrm{P}>0,05, \mathrm{~ns}$ \\
$1000 \mathrm{~dB}$ postop.-preop. & $6,07 \pm 12,89$ & $5,88 \pm 12,15$ & 0,93 & $\mathrm{P}>0,05, \mathrm{~ns}$ \\
$2000 \mathrm{~dB}$ postop.-preop. & $4,38 \pm 12,10$ & $7,84 \pm 11,19$ & 0,12 & $P>0,05, \mathrm{~ns}$ \\
$4000 \mathrm{~dB}$ postop.-preop. & $2,63 \pm 12,87$ & $3,48 \pm 9,68$ & 0,69 & \\
\hline
\end{tabular}


Table 3: Comparison of bone conduction means Group 1 and Group 2.

\begin{tabular}{lccc} 
& \multicolumn{1}{c}{ Mean Value \pm SD(dB) } & P Value \\
& Group 1 (Steroid +) & Group 2 (Steroid - ) & \\
\hline $\begin{array}{l}\text { Preop. bone conduction means } \\
\text { 500-1000-2000-4000 }\end{array}$ & $29,2 \pm 15,2$ & $25,9 \pm 12,84$ & 0,102 \\
$\begin{array}{l}\text { Postop. bone conduction means } \\
\text { 500-1000-2000-4000 }\end{array}$ & $25,3 \pm 13,4$ & $21,95 \pm 13,3$ & 0,20031 \\
$\begin{array}{l}\text { Comparison of Preop. And postop. } \\
\text { bone conduction means } \\
\text { Difference }\end{array}$ & $3,9 \pm 12,3$ & $3,95 \pm 9,1$ & 0,93842 \\
\hline
\end{tabular}

Table 4: Speech Discrimination Score Comparison of Group 1 and Group 2.

\begin{tabular}{lcccc}
\hline Speech Discrimination Score (\%) & Pre-operative & Post-operative & P Value & Result \\
\hline All patients & $87,37 \pm 10,6$ & $89,96 \pm 10,2$ & 0,14 & P $>0,05 \mathrm{~ns}$ \\
Group 1 (Steroid+) & $85,73 \pm 13,7$ & $92,1 \pm 10,09$ & 0,006 & P $<0,05^{*}$ \\
Group 2 (Steroid -) & $89,08 \pm 10,46$ & $87,56 \pm 16,62$ & 0,58 & P>0,05 ns \\
\hline
\end{tabular}

Table 5: Distribution of patients according to air-bone gap in Group 1 and Group 2

\begin{tabular}{lcccc}
\hline Postop ABG & $<10$ & 11-20dB & 21-30 & $>30$ \\
\hline Patients & 34 Patients (32\%) & 47 Patients (44,3\%) & 22 Patients (20,7\%) & 4 Patients (3,77 \%) \\
Group 1 (Steroid + ) & 12 Patients (21,4\%) & 26 Patients (46,4\%) & 16 Patients (\%28,5) & 2 Patients (3,57\%) \\
Group 2 (Steroid -) & 22 Patients (44\%) & 21 Patients (42\%) & 6 Patients (12\%) & 2 Patients (4\%) \\
\hline
\end{tabular}

at other frequencies. Güneş et al. observed an increase in the bony pathway conduction at all frequencies ${ }^{[8]}$. In our research, when all the cases were taken into consideration, the gain obtained in the average bony conduction at 500, 1000,2000 and $4000 \mathrm{~Hz}$ was $4.07 \pm 11.4 \mathrm{~dB}$, but regarding the $4000 \mathrm{~Hz}$ frequency, there was no average gain, whilst at all other frequencies, a significant improvement was observed.

Kisilevsky et al. likewise were unable to obtain any improvement at the $4000 \mathrm{~Hz}$ frequency in the bony pathway and this situation they attributed to a fall in the threshold for bony conduction as a result of surgical trauma to the inner ear [7]. Vincent and colleagues in similar fashion were unable to find improvement in the thresholds for bony conduction at $4000 \mathrm{~Hz}^{[9]}$.

We also think that the lack of improvement in bone conduction values at $4000 \mathrm{~Hz}$ may be due to the potential effect of operative trauma.

In our research, 4 patients (3.77\%) were found to have a hearing loss of greater than $15 \mathrm{~dB}$. Of these patients with a decline in the bony pathway, two came from Group 1, and the other two from Group 2. One such case (0.94\%) had nearly absolute hearing loss, but in fact no individual actually developed total loss of hearing.

If we compare our results with the literature, we can see that preoperative bone conduction values at 1000, 2000, and $4000 \mathrm{~Hz}$ and immediate postoperative bone conduction values were investigated in Riechelmann et al.'s ${ }^{[10]} \mathrm{se}-$ ries of 95 patients who underwent stapedotomy for otosclerosis with an erbium:YAG laser. Prophylactic perioperative prednisolone therapy did not improve immediate postoperative mean bone conduction thresholds and did not reduce the occurrence of early sensorineural hearing loss. 
They reached the conclusion that perioperative cortisone prophylaxis to prevent inner ear damage during stapes surgery in patients receiving perioperative steroid treatment is both ineffective and increases postoperative morbidity. In our study, it has also been demonstrated that the mean level of improvement in bony pathways between the group with corticosteroids and the group with no corticosteroids was similar. Therefore, routine administration perioperatively of corticosteroid therapy may not lead to significant difference in outcome for patients with otosclerosis.

A study performed by W. Schneider et al. ${ }^{[11]}$ on a guinea pig animal model, in which a microdrill was applied to the incus ossicle to create a sensorineural hearing loss, looked at whether methylprednisolone had any effect on the hearing loss resulting from the surgery. The authors concluded that for sensorineural hearing loss produced by contact of the microdrill with the ossicles, methylprednisolone administration did not confer any benefit.

The most widely employed parameter used to assess the effectiveness of surgery for otosclerosis is the discrepancy between air and bony conduction postoperatively (the "air-bone" gap (ABG)). A discrepancy of $10 \mathrm{~dB}$ or less between bony and air conduction in the postoperative period is taken as a criterion for success in multiple studies.

In multiple studies where the cases were grouped following surgery an $A B G$ of $\angle 10 \mathrm{~dB}$ was classified as very good, $20 \mathrm{~dB}$ as good, $20-30 \mathrm{~dB}$ acceptable and $>30 \mathrm{~dB}$ as indicating failure ${ }^{[12]}$. Examining the literature on this topic, we can observe that Vincent et al. [9] reported sucess in 94\% in 3050 studies, Quaranata et al. ${ }^{[13]}$ reported $85 \%$ success in 2134 cases, Kivlevsky et al. ${ }^{\left[{ }^{[7]}\right.}$ report $82 \%$ success in 1145 cases and De Brujin et al. ${ }^{[14]}$ reported a $71 \%$ success rate in 473 cases. In our research, when all cases are taken into account, the postoperative ABG was below $10 \mathrm{~dB}$ in 34 cases $(32 \%), 11-20 \mathrm{~dB}$ in 47 cases $(44.3 \%), 21-30 \mathrm{~dB}$ in 22 cases $(20.7 \%)$ and above $30 \mathrm{~dB}$ in 4 cases $(3.77 \%)$.

In group 1, which were the individuals given intraoperative i.v. steroids, the $\mathrm{ABG}$ was below $10 \mathrm{~dB}$ in 12 cases (21.4\%), $11-20 \mathrm{~dB}$ in 26 cases (46.4\%), 21-30dB in 16 cases $(28.5 \%)$ and above $30 \mathrm{~dB}$ in 2 cases $(3.57 \%)$. The control group (Group 2), which had not received steroids had 22 cases (44\%) with an ABG below 10dB, 21 cases (42\%) with
ABG of $11-20 \mathrm{~dB}, 612 \%)$ with $21-30 \mathrm{~dB}$ ABG and 2 cases (4\%) above $30 \mathrm{~dB}(4 \%)$.

In our research, intact bridge stapedotomy was performed in all cases by means of a $0.6 \mathrm{~mm}$ diameter fluoroplastic piston. The length of the piston used varied between 4-6 $\mathrm{mm}$, depending on the distance between the incus and the stapes footplate. In this way we can be sure we have an homogenous group for the study in terms of piston used and surgical approach. It is impossible to fully evaluate the effect on the bony pathway of administering steroids perioperatively due to the loss of the Carhart notch in the postoperative period from the audiograms of otosclerosis patients.

In addition, steroids given for reasons other than to counter the possibility of intraoperative trauma may negatively influence the conclusions. In our research, since it was a retrospective study, frequencies of over $4000 \mathrm{~Hz}$ were not evaluated. A prospective study to include higher frequencies needs to be undertaken to resolve this issue. These factors may be considered the limitations on our research. Although we were unable to demonstrate an effect of perioperative steroid use versus non-use on the level of hearing via the bony pathway, there are many studies in the literature using corticosteroids to prevent damage to the inner ear which have shown such an effect ${ }^{[15-17]}$. In this study the postoperative bony pathway average values demonstrate an improvement on the preoperative values at the level of statistical significance. However, the average improvement in the bony pathway between the group for which steroids were used and in which no steroids were used was shown to be similar. For this reason, the routine perioperative use of therapeutic steroids in patients with otosclerosis may not lead to a very meaningful result. At the same time, it may still be beneficial to use steroids perioperatively to prevent hearing loss in situations which predispose to inner ear damage. From our research on intraoperative steroid usage, when considering whether to provide a single dose of steroids, whether preoperatively or postoperatively, it is difficult to comment on how this may affect the gain in hearing that may be obtained from audiological surgery. 


\section{References}

1. Malkoc G, Dalgic A, Koc M. et al. Histopathological and audiological effects of mechanical trauma associated with the placement of an intracochlear electrode, and the benefit of corticosteroid infusion: prospective animal study. J Laryngol Otol. 2014;128:702-8. doi: 10.1017/ S002221511400156X.

2. American Academy of Otolaryngology- Head and Neck Surgery Foundation, Inc. Comittee on hearing and equilibrium guidelines for the evaluation of the results of treatment of conductive hearing loss. Otolaryngol Head and Neck Surg.1995;113:186-187. Doi:10.1016/S01945998(95)70103-6

3. Fisch U. Stapedotomy versus stapedectomy. 1982. Otol Neurotol. 2009;30:1160-5. Doi:10.1097/MAO.0b013e3181c1792d

4. Dinh CT, Haake S, Chen S. et al. Dexamethasone protects organ of corti explants against tumor necrosis factor-alpha-induced loss of auditory hair cells and alters the expression levels of apoptosis-related genes. Neuroscience. 2008;157:405-13. doi: 10.1016/j.neuroscience.2008.09.012.

5. Van De Water TR, Abi Hachem RN, Dinh CT. et al. Conservation of hearing and protection of auditory hair cells against trauma-induced losses by local dexamethasone therapy: molecular and genetic mechanisms. Cochlear Implants Int. 2010;11:42-55. doi: 10.1179/146701010X12671178390834.

6. Eshraghi AA, Adil E, He J. et al. Local dexamethasone therapy conserves hearing in an animal model of electrode insertion trauma-induced hearing loss. Otol Neurotol. 2007;28:842-9. Doi: 10.1097/mao.0b013e$31805778 \mathrm{fc}$

7. Kısılevsky VE, Dutt SN, Bailie NA, Halik JJ. Hearing results of 1145 stapedotomies evaluated with Amsterdam hearing evaluation plots. J Laryngol Otol 2009;123:730-736. doi: 10.1017/S0022215109004745.

8. Günes S, Kandoğan T, Olgun L, Gültekin G, Alper S, Çerçi U. Stapedotomy tecnique in otosclerosis surgery: A comparative longitudinal study of 220 cases examining also the impact piston lenghts $(0,4 \mathrm{~mm}$ vs 0,6 $\mathrm{mm}$ ) on hearing deficiency. Turch Arch Otolaryngol 2005;43:73-78.

9. Vincent R, Sperling NM, Oates J, Jindal M. Surgical findings and longterm hearing results in 3,050 stapedotomies for primary otosclerosis: a prospective study with the otology-neurotology database. Otol Neurotol
2006;27:25-47. Doi: 10.1097/01.mao.0000235311.80066.df

10. Riechelmann H, Tholen M, Keck T, Rettinger G. Perioperative glucocorticoid treatment does not influence early post-laser stapedotomy hearing thresholds. Am J Otol. 2000;21:809-12.

11. Schneider W, Gjuric M, Katalinic A, Buhr W, Wolf SR. The value of methylprednisolone in the treatment of an experimental sensorineural hearing loss following drill-induced ossicular chain injury: a randomized, blinded study in guinea-pigs. Acta Otolaryngol. 1998;118:52-5.

12. Denoyelle F, Daval M, Leboulanger N, Rousseau A, Roger G, Loundon $\mathrm{N}$, et al. Stapedectomy in children: causes and surgical results in 35 cases. Arch Otolaryngol Head Neck Surg 2010;136:1005-8. doi: 10.1001/ archoto.2010.170.

13. Quaranta N, Besozzi G, Fallacara RA, Quaranta A. Air and bone conduction change after stapedotomy and partial stapedectomy for otosclerosis. Otolaryngol Head Neck Surg. 2005;133:116-20. Doi: 10.1016/j. otohns.2005.03.011

14. de Bruijn AJ, Tange RA, Dreschler WA. Efficacy of evaluation of audiometric results after stapes surgery in otosclerosis. II. A method for reporting results from individual cases. Otolaryngol Head Neck Surg. 2001;124:84-9. Doi: 10.1067/mhn.2001.111600

15. Dinh CT, Haake S, Chen S, Hoang K, Nong E, Eshraghi AA. et al. Dexamethasone protects organ of corti explants against tumor necrosis factor-alpha-induced loss of auditory hair cells and alters the expression levels of apoptosis-related genes. Neuroscience. 2008;157:405-13. doi: 10.1016/j.neuroscience.2008.09.012.

16. Van De Water TR, Abi Hachem RN, Dinh CT, Bas E, Haake SM, Hoosien G. et al. Conservation of hearing and protection of auditory hair cells against trauma-induced losses by local dexamethasone therapy: molecular and genetic mechanisms. Cochlear Implants Int. 2010;11:42-55. doi: 10.1179/146701010X12671178390834

17. Eshraghi AA, Adil E, He J, Graves R, Balkany TJ, Van De Water TR. Local dexamethasone therapy conserves hearing in an animal model of electrode insertion trauma-induced hearing loss. Otol Neurotol. 2007;28:842-9. Doi: 10.1097/mao.0b013e31805778fc

This is an open access article distributed under the terms of the Creative Commons Attribution-NonCommercial-NoDerivs 3.0 Unported (CC BYNC-ND3.0) Licence (http://creativecommons.org/licenses/by-nc-nd/3.0/) which permits unrestricted noncommercial use, distribution, and reproduction in any medium, provided the original work is properly cited.

Please cite this article as: Çelik Ç, Ceylan M. E, Aliyeva A, Düzenli U, Dalgı̧̣ A. The Effect Of Perioperative I.v. Corticosteroids On Hearing Outcome Following Stapedotomy. ENT Updates 2018;8(2): 82-87. 